the financing by the State of a system of modernised mutually co-operating co-operative colonies. In other words, it plans to bring into existence an organisation of people who would be customers to one another, and thereby independent of fluctuations in general trade prosperity. Capt. Petavel claims that co-operative colonies for education would be the easiest type to establish, and that in India they would enable an ideal educational programme to be planned. They would revive in a modern form the old Indian Gurukul education system as was strenuously advocated by the late Sir Asutosh Mookerjee. In the educational colonies, three hours per day might be devoted to productive work of a suitable kind, which it is claimed is the first item in any ideal educationul programme. Another three hours devoted to organised games would serve to develop muscle, alertness and disciplined co-operation. In the ideal programme there would be time also for instruction conveyed by drama, song and similar methods. Class work need then occupy not more than four hours, leaving fourteen hours for rest and recreation. The colonies would be practically selfsupporting, since the pupils would cultivate the land that would give them and those who taught them their food. In the Indian rura] districts, the educational 'united communities' would be centres also of technical training of all kinds. They would be the seed farms, stock farms, demonstration farms and centres of rural reconstruction generally.

\section{The Ministry of Health in $1933-34$}

THE fifteenth Annual Report of the Ministry of Health was issued on August 11 (Cmd. 4664. London : H.M. Stationery Office. 6s. net). The Report, which relates to the year ended March 31, 1934, is divided into six parts-public health, housing and town planning, local government and local finance, administration of the poor law, national health insurance and contributory pensions, and the Welsh Board of Health. As in previous years, the Annual Report of the Chief Medical Officer of the Ministry is published separately. During the twelve months, private enter. prise built without subsidy 207,869 houses, which constitutes a record. The opportunity has been taken to include in the Report a full review of the public health services under the conditions created by the Local Government Act, 1929. The number of samples of food analysed by public analysts during the year 1933 was 138,171 , of which 7,601 samples were roported as adulterated or not up to standard, a percentage of $5 \cdot 5$, being a slight increase over the two previous years. As regards infectious diseases, the notable features of the year were an increase in the prevalence of scarlet fever, concurrently with an increase in the prevalence in diphtheria, an increase in the prevalence of and mortality from cerebro-spinal fever, and a decline in the incidence of smalıpox.

\section{The Giorgi System of Units}

AN interesting note on the metre, kilogram, second and 'another unit' system of units by Prof. G. Giorgi has been published iny the International Electro- technical Commission (I.E.C.) the central office of which is at 28, Victoria Street, S.W.1. This system of units has already been described in NATURE of April 21, p. 597. The committee for electric and magnetic units voted last year unanimously in favour of a proposall to arrange the system of practical electrotechnic units into a complete absolute system usually called the M.K.S. system. In this paper, Giorgi describes the three well-known groups of units, the C.G.S. electrostatic, the C.G.S. electromagnetic and the group of practical units. $\mathrm{He}$ commends the national system of units devised by Heaviside, in which the $4 \pi$ is displaced and a perfect duality between electric and magnetic formulm is secured. The theory of physical dimensions is better understood than it was fifty years ago. No one now believes that everything in the physical world depends necessarily on three fundamental quantities, length, mass and time. Giorgi shows that by taking the ampere, or the volt or the coulomb as the fourth unit, he can build up a complete absolute system from four fundamental units. This set of units is neither electrostatic nor electromagnetic; it is in agreement with the principle of duality and can be used with either rational or non-rational derived units. All units of the system lie between the smallest and largest magnitudes that present science has to measure. It will simplify the learning of the theory of electricity by students of electrical engineering. No proposal is made to discard the existing systems of units. Each one will be employed according to the requirements of the subject and the preference of the user. Future practice will show which is the most convenient.

\section{Before Papyrus: Beyond Rayon}

AN interesting and brightly written paper by Dr. G. J. Esselen, the president of Inc. Chemical and Research Development of Boston, is published in the Journal of the Franklin Institute of March. It is entitled "Before Papyrus .. Beyond Rayon" kayon a few years ago was universally known as artificial silk. The basic chemical substance to which the writer refers is cellulose. It forms the structural framework of all vegetable life and is the raw material of great industries. The reason why the derivatives of cellulose were so slow in developing is that it is only a few years ago since its empirical composition was discovered. Transparent sheets of cellulose plastic are used in the manufacture of the laminated 'glass used in automobiles. A recent discovery has so lowered the cost of the manufacture of cellulose acetate plastic that at the present time more than 70 per cent of all the laminated 'glass' manufactured in the United States is made from it. They also make bullet-proof 'glass' composed of five laminations, the centre one being a piece of plate glass about $\frac{3}{4}$ in. in thickness. It is being used for the windows of armoured cars and cashiers' cages in banks. In 1910, no rayon was being made in the United States. In 1931, 144 million pounds were produced. Methods of manufacturing rayon are continually improving, greatly increasing its strength and its resistance to 